\title{
Storage and allogeneic transplantation of peripheral nerve using a green tea polyphenol solution in a canine model
}

\author{
Ken Nakayama', Ryosuke Kakinoki ${ }^{2,3^{*}}$, Ryosuke Ikeguchi ${ }^{4}$, Tomoyuki Yamakawa ${ }^{5}$, Soichi Ohta ${ }^{2}$, Satoshi Fujita ${ }^{2}$,
} Takashi Noguchi², Scott FM Duncan ${ }^{6}$, Suong-Hyu Hyon', Takashi Nakamurara

\begin{abstract}
Background: In our previous study, allogeneic-transplanted peripheral nerve segments preserved for one month in a polyphenol solution at $4^{\circ} \mathrm{C}$ could regenerate nerves in rodents demonstrated the same extent of nerve regeneration as isogeneic fresh nerve grafts. The present study investigated whether the same results could be obtained in a canine model.

Methods: A sciatic nerve was harvested from a male beagle dog, divided into fascicules of $<1.5 \mathrm{~mm}$ diameter, and stored in a polyphenol solution $(1 \mathrm{mg} / \mathrm{ml})$ for one month at $4^{\circ} \mathrm{C}$. The nerve fascicles were transplanted into 10 female beagle dogs to bridge $3-\mathrm{cm}$ right ulnar nerve gaps. In the left ulnar nerve in each dog, a 3-cm nerve segment was harvested, turned in the opposite direction, and sutured in situ. Starting one day before transplantation, the immunosuppressant FK506 was administered subcutaneously at doses of $0.1 \mathrm{mg} / \mathrm{kg}$ daily in four dogs (PA0.1 group), $0.05 \mathrm{mg} / \mathrm{kg}$ daily in four dogs (PA0.05 group), or $0.05 \mathrm{mg} / \mathrm{kg}$ every other day in two dogs (PA0.025 group). Twelve weeks after surgery, electrophysiological and morphological studies were performed to assess the regeneration of the right and left ulnar nerves. The data for the right ulnar nerve were expressed as percentages relative to the left ulnar nerve. Polymerase chain reaction (PCR) was used to identify the sexdetermining region of the $Y$-chromosome (Sry) and $\beta$-actin to investigate whether cells of donor origin remained in the allogeneic nerve segments. FK506 concentration was measured in blood samples taken before the animals were killed.
\end{abstract}

Results: The total myelinated axon numbers and amplitudes of the muscle action potentials correlated significantly with the blood FK506 concentration. Few axons were observed in the allogeneic-transplanted nerve segments in the PA0.025 group. PCR showed clear Sry-specific bands in specimens from the PA0.1 and PA0.05 groups but not from the PA0.025 group.

Conclusions: Successful nerve regeneration was observed in the polyphenol-treated nerve allografts when transplanted in association with a therapeutic dose of FK506. The data indicate that polyphenols can protect nerve tissue from ischemic damage for one month; however, the effects of immune suppression seem insufficient to permit allogeneic transplantation of peripheral nerves in a canine model.

\section{Background}

Autogenous nerve grafting is a widely accepted method for treating peripheral nerve injuries with nerve deficits. However, the sources of donor nerves are limited, and

\footnotetext{
* Correspondence: kakinoki@kuhp.kyoto-u.ac.jp

${ }^{2}$ Department of Orthopedic Surgery, Graduate School of Medicine, Kyoto University, Kyoto, Japan

Full list of author information is available at the end of the article
}

donor site morbidity is inevitable. The shortage of nerve sources for transplantation is a serious problem in autogenous nerve grafting. Nerve allografts performed in association with the administration of an immunosuppressant provide an alternative to autogenous nerve grafts $[1,2]$. However, nonspecific immunosuppressive treatments are often followed by opportunistic infection of nonpathological viruses or neoplasm formation [3-5].

\section{Biomed Central}


It is controversial whether immunosuppressants should be administered with nerve allografts when repairing peripheral nerve injuries with nerve deficits because such injuries are not usually life threatening.

Green tea polyphenols are intriguing because they protect tissues from ischemia, have antineoplastic and anti-inflammatory effects, and suppress immune responses [6-9]. In our previous studies, peripheral nerve allografts preserved for one month in a green tea polyphenol solution were able to regenerate nerves in a manner similar to that of fresh nerve autografts in a rodent model, suggesting that peripheral nerve segments treated with green tea polyphenols might provide an alternative to autogenous nerve grafts. The observation that the nerve segments could be preserved for one month in the green tea polyphenol solution suggested that treatment with polyphenols could change allogeneic nerve transplantation from an emergency operation to a scheduled operation. However, in our semiquantitative PCR study, only $14 \%$ of cells survived in the polyphenol-treated allografts, whereas about $62 \%$ of cells survived in the fresh nerve isografts [10]. These results suggested that nerve regeneration from the polyphenoltreated nerve allografts would be inferior to that from fresh nerve isografts when applied to long nerve gaps or in highly developed animals such as dogs, primates, and human beings. We hypothesized that the combination of immunosuppressants administered with polyphenol treatment would lead to successful nerve regeneration with nerve allografts.

In the present study, we performed 3-cm-long allogeneic nerve grafts on the right ulnar nerve and $3-\mathrm{cm}$ long isogeneic nerve grafts on the left ulnar nerve in a canine model given one of three doses of an immunosuppressant (FK506) [11-13]. We examined the relationship between nerve regeneration in the nerve allografts and blood FK506 level to investigate whether polyphenol treatment can reduce the dosage of the immunosuppressant needed to obtain successful nerve regeneration in the allogeneic nerve transplant.

\section{Methods}

\section{Polyphenols}

A polyphenol mix extracted from green tea was purchased from PFI, Inc. (Kyoto, Japan). It comprised mainly (-)-epigallo-catechin-3-O-gallate (28\%), (-)-gallocatechin-3-O-gallate (11.6\%), (-)-epicatechin-3-O-gallate (4.6\%), (-)-epigallocatechin (15.0\%), (+)-gallocatechin (14.8\%), (-)-epicatechin (7.0\%), and (+)-catechin (9.5\%), and its purity exceeded $90 \%$.

\section{Animals}

One male beagle dog (18 kg) and 10 female beagle dogs $(15 \mathrm{~kg})$ were used in this study. The male animal was purchased from a different breeder from the one supplying the female animals. Each animal was acclimatized before the surgical procedures, housed in a separate cage, and given standard dog food and water three times a day. All experiments were performed in accordance with the guidelines of the Animal Research Committee, Graduate School of Medicine, Kyoto University, Japan. The female animals were divided into three groups and received subcutaneous injections of one of three doses of FK506: $0.1 \mathrm{mg} / \mathrm{kg}$ every day to four animals (PA0.1 group), $0.05 \mathrm{mg} / \mathrm{kg}$ every day to four animals (PA0.05 group), and $0.05 \mathrm{mg} / \mathrm{kg}$ every other day to two animals (PA0.025 group).

\section{Surgery \\ Anesthesia}

Animals were sedated with $0.2 \mathrm{mg} / \mathrm{kg}$ acepromazine given subcutaneously. After intubation, general anesthesia was induced by inhalation with $5 \%$ isoflurane. After confirming that the animals were nonresponsive to stimulation of the eyelashes, surgery started.

\section{Harvesting nerve allografts and preservation}

The male animal was placed in the prone position, and the sciatic nerve was harvested. The sciatic nerve was exposed from the sciatic notch to the popliteal fossa in the interval between the hamstring muscles to obtain a 10-cm-long nerve segment in the midthigh level. The nerve segment was separated into fascicles under an operating microscope, and the fascicles were harvested. The diameter of the fascicles was $<1.5 \mathrm{~mm}$, and the length was $>5 \mathrm{~cm}$ [10]. The fascicles were immersed at $4^{\circ} \mathrm{C}$ in Dulbecco's modified Eagle's medium (DMEM) containing the polyphenols $(1 \mathrm{mg} / \mathrm{ml})$ for one week and then transferred to DMEM solution alone and immersed in DMEM for three more weeks.

\section{Transplantation of the preserved nerve segments}

Recipient female animals were anesthetized in the supine position as described above, and a skin incision was made on the right lower forelimb. The ulnar nerve was exposed by retracting the ulnar carpal flexor muscle medially and the digital flexors laterally. A 2.5-cm-long ulnar nerve segment was removed at the midportion of the lower forelimb. The sciatic nerve fascicles harvested from the male animal and preserved for one month were taken from the DMEM solution. Because the diameter of the ulnar nerve was almost 2 $\mathrm{mm}$ in the middle of the lower forelimb, two fasciclesa thick fascicle of $1.2-1.5-\mathrm{mm}$ diameter and a thin fascicle of $0.5-0.8-\mathrm{mm}$ diameter-were transplanted as the nerve graft. The length of the nerve grafts was adjusted to $3 \mathrm{~cm}$ just before transplantation. Each $3-\mathrm{cm}$-long nerve segment comprising the two fascicles was interposed between the proximal and distal nerve stumps of the ulnar nerve using 10-0 epineural sutures in the 


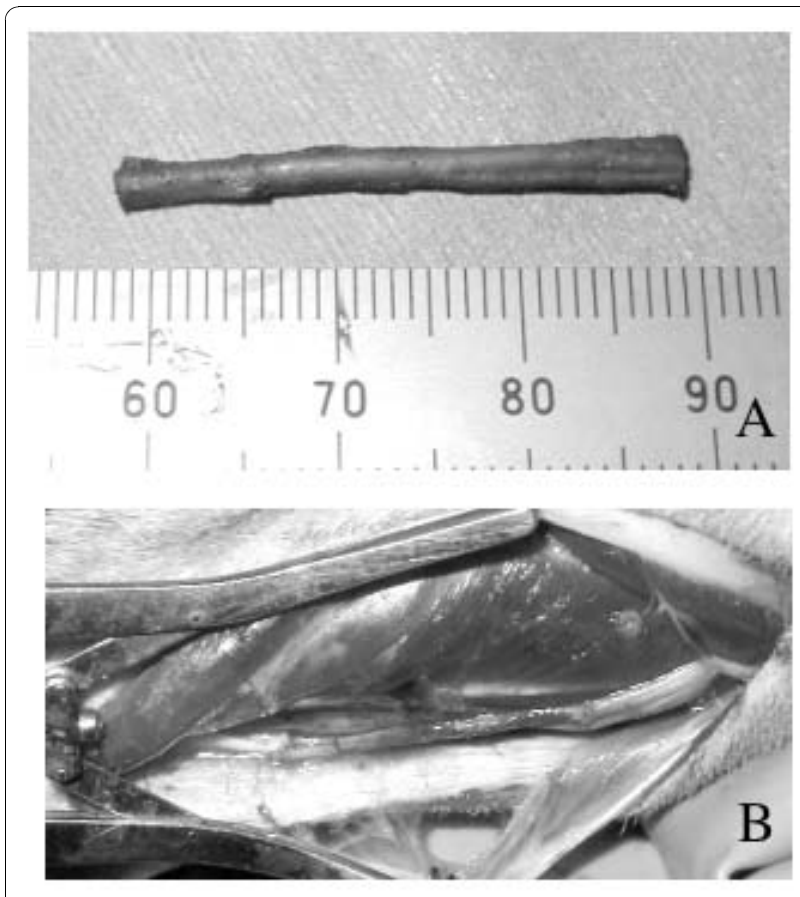

Figure 1 Nerve transplantation. A nerve allograft comprising two fascicles of the donor sciatic nerve. (B) An intraoperative photograph of allogeneic nerve transplantation. Two fascicles of the donor sciatic nerve were interposed between the proximal and distal stumps of the ulnar nerve in the middle of the right lower forearm.

right forelimb (the model for allogeneic nerve transplantation) (Figure 1).

In the left forelimb, the ulnar nerve was exposed in the same way as in the right forelimb. A 3-cm-long nerve segment was removed in the middle of the lower forelimb. The nerve segment was turned in the opposite direction and sutured in situ (the model for isogeneic nerve transplantation).

In all animals, FK506 administration was started one day before the transplantation.

\section{Electrophysiological study}

Twelve weeks after nerve transplantation, all recipient animals were anesthetized as described above. The right ulnar nerve was exposed and stimulated $3 \mathrm{~cm}$ distal to the elbow joint (S1) and $2 \mathrm{~cm}$ proximal to the wrist joint (S2) with a bipolar silver electrode. A pair of plate electrodes was fixed over the prominence of the muscles at the base of the most ulnar digit (hypothenar muscles) to check for the presence of action potentials in the muscles. The motor nerve conduction velocity (MNCV) was calculated for both types of evoked action potentials stimulated at S1 and S2. The amplitude (peak to peak) of action potentials evoked in the hypothenar muscles with the supramaximal electric stimulation was measured. The same procedure was performed on the left forelimb.

The values for the action potential amplitude evoked in the hypothenar muscles and the MNCV for the right ulnar nerve (the allogeneic-transplanted nerve) were expressed as percentages of the values for the left ulnar nerve (the isogeneic-transplanted nerve) and are presented as \%action potential amplitude and \%MNCV, respectively, for each animal.

\section{Morphological study}

After the electrophysiological study, a 1-cm-long nerve segment was harvested from both ulnar nerves $1 \mathrm{~cm}$ distal to the transplanted nerve segments, fixed in $1 \%$ glutaraldehyde and $1.44 \%$ paraformaldehyde, postfixed with $1 \%$ osmic acid, and embedded in epoxy resin. Transverse sections ( $1 \mu \mathrm{m}$ thick) were taken from the midportion of the segment. Transverse sections were harvested about $1.5 \mathrm{~cm}$ distal to the distal neurorrhaphy of the transplanted nerve segments. The section was stained with $0.5 \%(\mathrm{w} / \mathrm{v})$ toluidine blue solution and examined by light microscopy. Light microscope images of the specimens were downloaded to a personal computer using Photoshop software (Version 5; Adobe Systems Inc., San Jose, CA). The total number of myelinated axons and mean myelinated axon diameter were calculated on each specimen using Image Pro Plus software (Media Cybernetics, Silver Spring, MD).

Briefly, the entire neural area (a) of each specimen was calculated on an image. Six or seven fields were chosen at random so that the area analyzed would be $>20 \%$ of the entire neural area of each specimen. The number of myelinated axons, the neural area, and the shortest diameter of each myelinated axon were calculated for each field. The total number of myelinated axons (b) and neural areas (c) of six or seven fields were calculated. The total number of myelinated axons in each specimen was estimated as $b \times a / c$. The mean myelinated axon diameter (in $\mu \mathrm{m}$ ) is expressed as the average value of the shortest diameter of all myelinated axons in the six or seven fields $[10,14,15]$.

The total axon number and mean axon diameter of the right ulnar nerve (the nerve allograft model) are expressed as percentages of those of the left ulnar nerve (the nerve isograft model) and are presented as \%total axon number and \%mean axon diameter, respectively, for each animal.

\section{Measurement of blood FK506 concentration and sacrifice of animals}

After harvesting the nerve specimens for the morphological study, a 5-ml blood sample was obtained from each animal using percutaneous needle puncture of the heart. A lethal dose of pentobarbital $(100 \mathrm{mg} / \mathrm{kg} /$ body 
weight) was then injected into the heart to kill the animals. Blood FK506 concentration was measured in the recipient animals by enzyme-linked immunosorbent assay (ELISA) using an anti-FK506 monoclonal antibody [16].

\section{Genomic study}

Polymerase chain reaction (PCR) was used to investigate the origin of cells in the nerve allografts in the recipient animals using primers specific for the sex-determining region of the canine $\mathrm{Y}$-chromosome $(S r y)$ and $\beta$-actin genes. After the electrophysiological study, a 1-cm-long nerve segment was taken from the center of each nerve allograft in the right ulnar nerve of all animals. Genomic DNA was extracted from each nerve segment using phenol-chloroform extraction and quantified spectrophotometrically. PCR amplification was performed as described below. The reaction mixture included 0.001 $\mu \mathrm{g}$ of genomic DNA, 0.5 U Taq DNA polymerase (AmpliTaq Gold, PerkinElmer Cetus, Shelton, CT), 1 $\mathrm{pM}$ of each oligonucleotide primer, $2 \mu \mathrm{l}$ of a $2.5 \mathrm{mM}$ solution of each dNTP, $2.5 \mu \mathrm{l}$ of $10 \times$ PCR buffer, and $1.5 \mu \mathrm{l}$ of $1.5 \mathrm{mM} \mathrm{MgCl} 2$ in a final volume of $25 \mu \mathrm{l}$. The primer sequences used were as follows: canine Sry gene, 5'-CTC GCG ATC AAA GGC GCA AGA T-3' and 5'TTC GGC TTC TGT AAG CAT TTT C-3'; and canine $\beta$-actin gene, 5 '-TCC TGT GGC ATC CAC GAA ACT3' and 5'-GAA GCA TTT GCG GTG GAC GAT-3'. PCR was performed in a thermal cycler (PerkinElmer Cetus) for 32 cycles of denaturation $\left(94^{\circ} \mathrm{C}, 45 \mathrm{~s}\right)$, annealing $\left(60^{\circ} \mathrm{C}, 45 \mathrm{~s}\right)$, and extension $\left(72^{\circ} \mathrm{C}, 60 \mathrm{~s}\right)$. The product was analyzed by electrophoresis on a $2 \%$ agarose gel followed by ethidium bromide staining $[17,18]$.

\section{Statistical analysis}

Correlation coefficients were calculated between the blood FK506 level and the \%action potential amplitudes, \%MNCVs, \%total axon numbers, and \%mean axon diameters using SPSS for Windows (Version 17.0, SPSS Inc., Chicago, IL). A p-value $<0.05$ was considered significant.

\section{Results}

\section{Electrophysiological study}

Twelve weeks after transplantation, all animals in the PA0.1 and the PA0.05 groups displayed evoked action potentials in the right hypothenar muscles, whereas no animal in the PA0.025 group displayed evoked action potentials in the right hypothenar muscles. The mean \% muscle action amplitude was 100\% (range 69.8-151.4\%) in the PA0.1 group and $34.7 \%$ (range 9.7-60.6\%) in the PA0.05 group. The mean \%MNCV was $80.1 \%$ in the PA0.1 group and $61.4 \%$ in the PA0.05 group. The blood FK506 concentration and \%muscle action potential amplitudes correlated significantly (correlation coefficient $=0.88, \mathrm{p}=0.002$ ). The blood FK506 concentration and $\% \mathrm{MNCV}$ did not correlate significantly (correlation coefficient $=0.70, \mathrm{p}=0.054$ ) (Figure 2).

\section{Morphological study}

There were marked differences in the pattern of nerve regeneration between the groups (Figure 3). Myelinated axons were seen in all transverse sections taken about $1.5 \mathrm{~cm}$ distal to the distal neurorrhaphy of the right ulnar nerves in the PA0.1 and PA0.05 groups, whereas few myelinated axons were observed in the nerve allografts of the PA0.025 group. This finding suggests that the polyphenol treatment combined with the subcutaneous administration of FK506 at the low dose of 0.05 $\mathrm{mg} / \mathrm{kg}$ every other day did not prevent immune rejection of the transplanted nerve segments. The mean \% total axon numbers were $86.8 \%$ in the PA0.1 group, $35.0 \%$ in the PA0.05 group, and $0 \%$ in the PA0.025 group. The average \%mean axon diameters were $80.2 \%$ in the PA0.1 group, $52.2 \%$ in the PA0.05 group, and $0 \%$ in the PA0.025 group. The blood FK506 concentration correlated significantly with the \%total axon number (correlation coefficient $=0.91, \mathrm{p}<0.001$ ). The FK506 concentration did not correlate significantly with the \% mean axon diameters (correlation coefficient $=0.56, \mathrm{p}=$ 0.153) (Figure 4).

\section{Blood FK506 concentration}

The blood FK506 concentration differed markedly between dogs, even within the same group. The concentrations were $11-19 \mathrm{ng} / \mathrm{ml}$ (mean $14.6 \mathrm{ng} / \mathrm{ml}$ ) in the PA0.1 group, 4-9 $\mathrm{ng} / \mathrm{ml}$ (mean $6.9 \mathrm{ng} / \mathrm{ml}$ ) in the PA0.05 group, and 1.0 and $2.5 \mathrm{ng} / \mathrm{ml}$ in the two dogs in the PA0.025 group.

\section{Genomic study}

Sufficient genomic DNA to perform semiquantitative PCR was extracted from all nerve allograft specimens in each group. The concentrations of the extracted DNA were $321.2-406.5 \mu \mathrm{g} / \mathrm{ml}$ in the PA0.1 group, 272.8-359.7 $\mu \mathrm{g} / \mathrm{ml}$ in the PA0.05 group, and $81.8 \mu \mathrm{g} / \mathrm{ml}$ and 120.6 $\mu \mathrm{g} / \mathrm{ml}$ in the PA0.025 group. Less DNA was extracted from nerve specimens in the PA0.025 group than in the PA0.1 and PA0.05 groups. PCR products specific to $\beta$-actin were detected in all samples in all groups. Sryspecific bands were detected in all samples in the PA0.1 and PA0.05 groups, but neither specimen demonstrated the Sry-specific band in the PA0.025 group (Figure 5). These results indicate that cells originating from the donor nerves remained in the nerve allografts in the PA0.1 and PA0.05 groups but that no cells of donor origin survived in the nerve allografts in the PA0.025 group. 
(\%) \%Muscle Action Potential

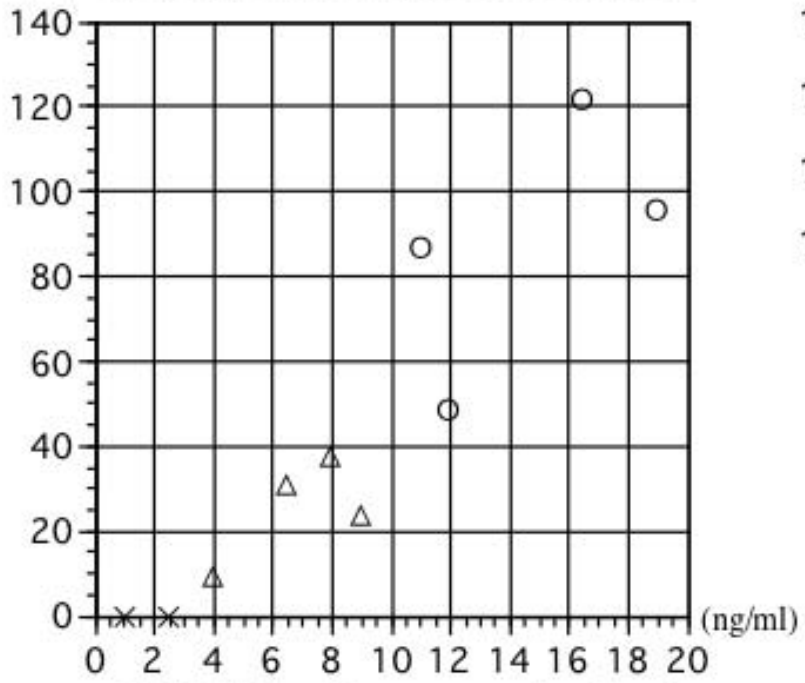

FK506 blood concentration level
(\%) $\quad \% \mathrm{MNCV}$

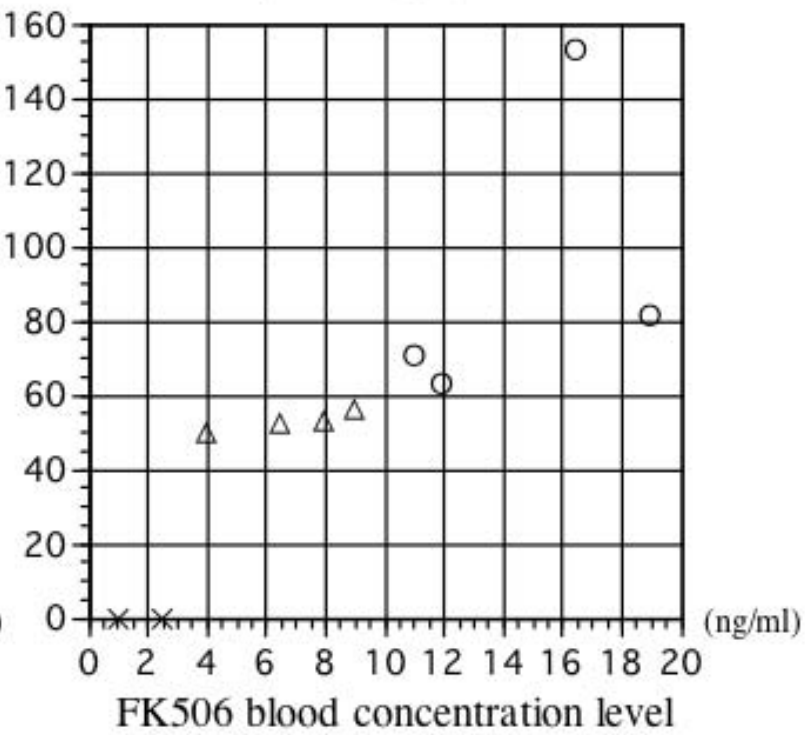

\section{O: PL0.1, $\triangle$ : PL0.05, X: PL0.025}

Figure 2 Electrophysiological study. Blood FK506 concentration ( $\mathrm{x}$-axis) and amplitude of action potentials evoked in the hypothenar muscles (y-axis) of each animal 12 weeks after transplantation. The FK506 concentration correlated significantly with the amplitude of the muscle action potentials (correlation coefficient $=0.88, p=0.002$ ). (B) Blood FK506 concentration ( $x$-axis) and motor nerve conduction velocity ( $y$-axis) of each animal 12 weeks after transplantation. The FK506 concentration did not correlate significantly with the MNCV (correlation coefficient $=0.70, p=$ 0.054).
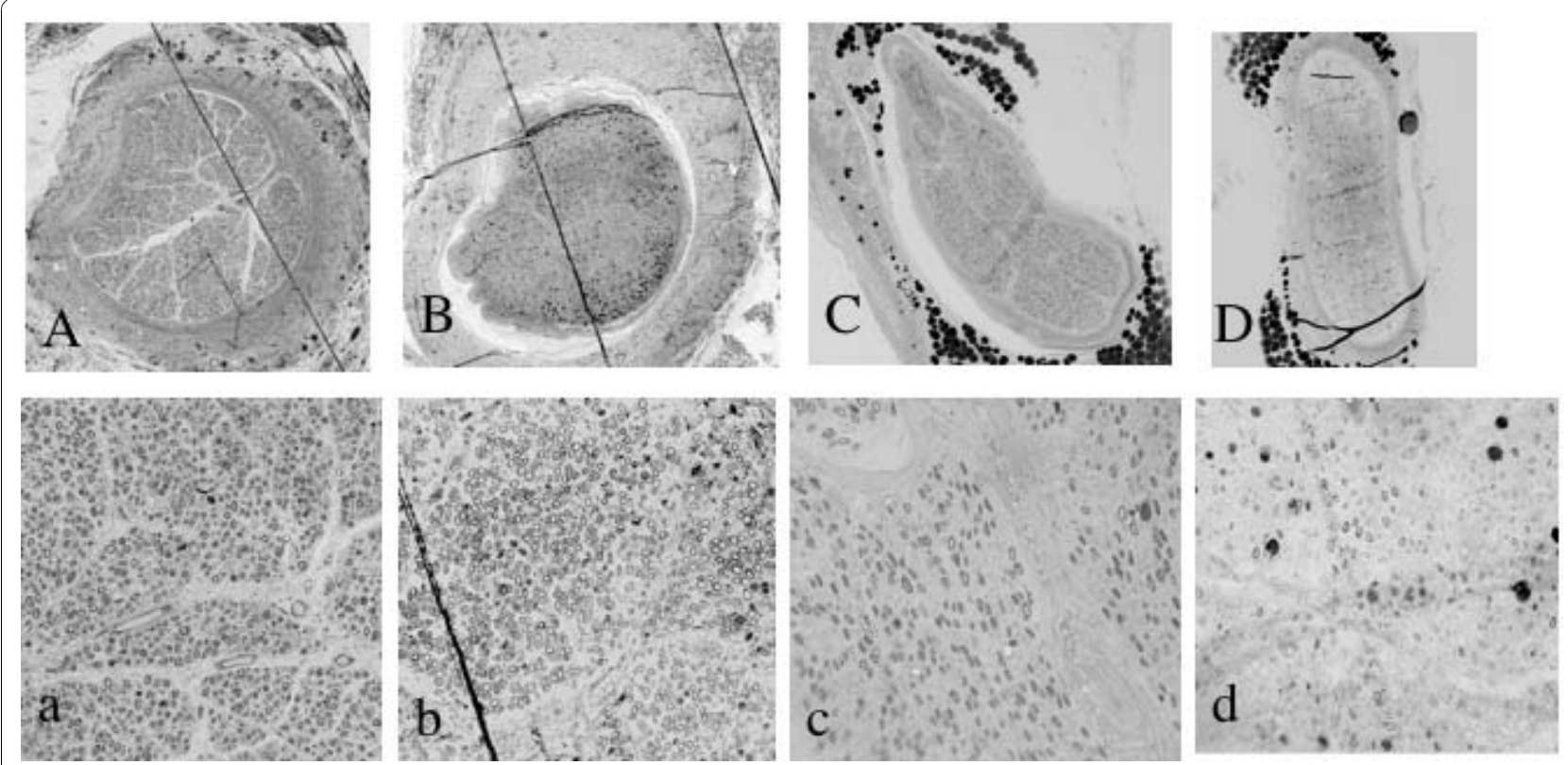

Figure 3 Morphological study. Light microscopic examination of transverse sections of the left ulnar nerve $1.5 \mathrm{~cm}$ distal to the distal neurorrhaphy of the nerve isograft ( $A, a)$ and allografts (B-D and b-d) 12 weeks after transplantation. (A-D) 100x magnification and a-d; 400x magnification. ( $A$, a) Nerve isograft in the PL0.1 group; $(B, b)$ nerve allografts in the PL0.1 group; $(C, C)$ nerve allografts in the PL0.05 group; $(D, d)$ nerve allografts in the PL0.025 group. ( $D, d)$ A very few myelinated axons were seen in the PL0.025 group. 


\section{(\%) \% Total Axon Number}

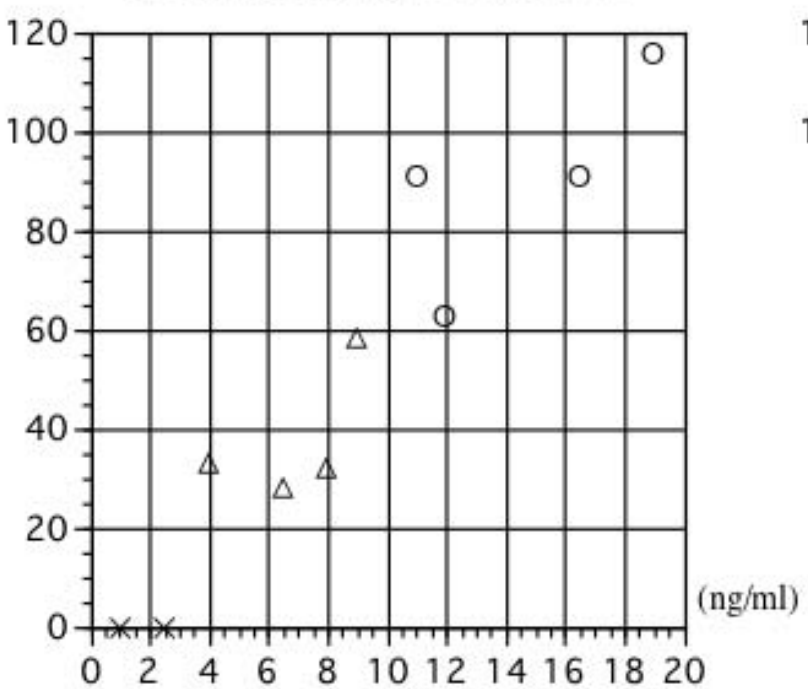

FK506 blood concentration level
(\%) \% Mean Axon Diameter

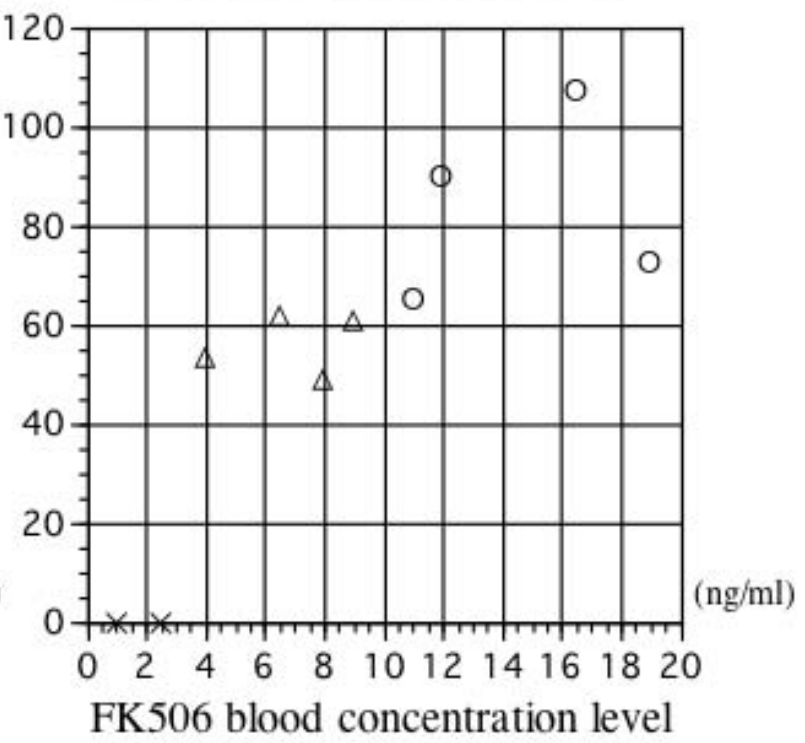

\section{O: PL0.1, $\triangle$ : PL0.05, X: PL0.025}

Figure 4 Morphological study with blood FK $\mathbf{5 0 6}$ concentration. Blood FK506 concentration (x-axis) and \%-total axon number (y-axis) of each animal 12 weeks after transplantation. The FK506 concentration correlated significantly with the number of regenerated axons (correlation coefficient $=0.88, p=0.002$ ). The \%-total axon number of each animal is expressed as the percentage of the total myelinated axon number in the right ulnar nerve divided by that in the left ulnar nerve. (B) Blood FK506 concentration (x-axis) and \%-mean axon diameter (y-axis) of each animal 12 weeks after transplantation. The FK506 concentration did not correlate significantly with the mean axon diameter (correlation coefficient $=0.70, p=0.054$ ). The \%-mean axon diameter of each animal is expressed as the percentage of the mean myelinated axon diameter in the right ulnar nerve (allogeneic nerve transplantation) divided by that in the left ulnar nerve (isogeneic nerve transplantation).

\section{Discussion}

The present study demonstrated that the extent of nerve regeneration of nerve allografts preserved in polyphenols for one month in association with the administration of $0.1 \mathrm{mg} / \mathrm{kg} /$ day of FK506 was more than $80 \%$ of that achieved with fresh nerve isografts. The \%total myelinated axon number and \%muscle action potential amplitude correlated strongly with the blood FK506 concentration in the recipient animals. PCR of the Sry region showed that cells originating in the allogeneic-transplanted nerve segments survived in the transplanted segments in dogs given $0.05 \mathrm{mg} / \mathrm{kg} /$ day of FK506.

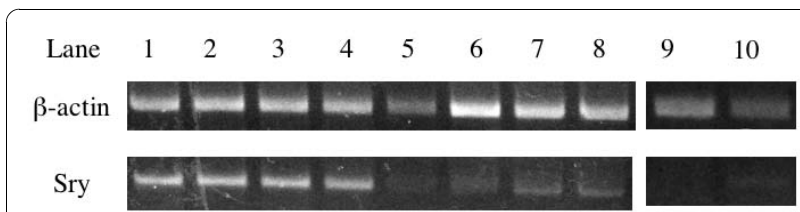

Figure 5 Genomic study. PCR specific to canine Sry and $\beta$-actin. (Lanes 1-4) PL0.1 group, (lanes 5-8) PL0.05 group, (lanes 9 and 10) PL0.025 group. (Upper row) $\beta$-actin-specific bands, (lower row) Sryspecific bands. $\beta$-actin-specific bands, but not Sry-specific bands, were seen in the specimens from the PL0.025 group.
FK506 (tacrolimus) is an immunosuppressant drug used widely in humans to prevent immune rejection of organ or tissue transplants [11-13]. The clinical literature shows that in humans, a dose of $10-20 \mathrm{ng} / \mathrm{ml}$ of FK506 is adequate to prevent rejection and that this dose is less than that associated with adverse effects following allogeneic organ or tissue transplantation [11-13]. We used a smaller dose in our study. Oike and Talpe reported that a blood FK506 concentration of 7$20 \mathrm{ng} / \mathrm{ml}$ led to successful allogeneic liver transplantation in miniature swine that were genetically semi-identical $[19,20]$. We observed nerve regeneration $>80 \%$ of that of the isogeneic nerve transplantation in the PA0.1 group, whose blood FK506 concentrations were $>10$ $\mathrm{ng} / \mathrm{ml}$. Previous studies showed that nerve regeneration through fresh nerve allografts in association with a therapeutic dose of FK506 was similar to that of fresh nerve isografts $[21,22]$. Dogs transplanted with isogeneic sciatic nerve fascicles to the ulnar nerve might demonstrate almost the same level of nerve regeneration as those observed in the PA0.1 group.

High doses of FK506 have an anti-ischemic effect, and lower doses that maintain the blood FK506 concentration 
at $10-20 \mathrm{ng} / \mathrm{ml}$ do not show a tissue-protective effect against ischemia [23]. Polyphenols protected the nerve segments from ischemic damage when the transplanted nerve segments were preserved for one month. We wondered whether the polyphenol treatment of the transplanted nerve segments contributed to the suppression of immunological reactions following the allogeneic transplantation. Although the precise mechanisms of immunosuppression by polyphenols are not understood fully, several papers have suggested that epigallocatechin gallate (EGCG), the main component of polyphenols, has immunosuppressive actions [24-27]. Our previous study using a rat model demonstrated successful nerve regeneration in polyphenol-treated nerve segments transplanted between major histocompatibility-mismatched rats, although only $14 \%$ of the cells of donor origin remained in the nerve segments 12 weeks after the transplantation [10]. The degree of nerve regeneration using nerve allografts treated with polyphenols correlated significantly with the blood FK506 concentration in dogs in our present study. The immunosuppressive effects of polyphenols might not be strong enough to prevent immune system-induced tissue rejection following allogeneic transplantation in dogs, which have a more highly developed immune system compared with rodents.

In the present study, the donor sciatic nerve segment was divided into fascicles of $<1.5 \mathrm{~mm}$, which were used for transplantation. Our previous studies demonstrated that immersion of a large-diameter nerve segment in the polyphenol solution for one month at $4^{\circ} \mathrm{C}$ was associated with the destruction of Schwann cells deeper than $0.7-0.8 \mathrm{~mm}$ below the perineural surface of the nerve segment. We suspected that the permeability of polyphenols into the peripheral nerve segments was < $0.7-0.8 \mathrm{~mm}$ from the perineural surface of nerves. The study revealed that the sciatic nerve segment should be divided into fascicles of $<1.4-1.6 \mathrm{~mm}$ before the polyphenol treatment [15]. It is known that FK506 has neuroprotective and neuroregenerative effects $[28,29]$. In the present study, we calculated the electrophysiological and morphological data of the nerve allografts as percentages relative to the nerve isografts in the contralateral forelimb to minimize the facilitative effect of FK506 on nerve regeneration.

Axons extended successfully through the nerve allografts that had been immersed in the polyphenol solution for one month when transplanted in association with a therapeutic dose of FK506 in a canine model. Although polyphenols have a strong anti-ischemic action, the ability to suppress immune rejection may not be strong enough to suppress the immunological rejection following allogeneic transplantation in animals such as the dog, which has a highly developed immune system.

\section{Conclusions}

In contrast to our previous findings in a rodent model using 2-cm-long nerve allografts, immersion of nerve segments in the polyphenol solution alone did not prevent immune rejection following the allogeneic transplantation of the segments in dogs. Our data suggest that polyphenol immersion in association with a therapeutic dose of FK506 might lead to successful nerve regeneration in higher animals. The polyphenols protected the nerve allografts from ischemic damage but did not completely suppress immune rejection episodes induced by the allotransplantation against the grafts.

\section{Acknowledgements}

We received a grant-in-aid for scientific research from Japan Society for the Promotion of Science (Scientific Research C 20314198 in 2008) to perform this study.

\section{Author details}

'Department of Orthopedic Surgery, Shizuoka General Hospital, Shizuoka, Japan. ${ }^{2}$ Department of Orthopedic Surgery, Graduate School of Medicine, Kyoto University, Kyoto, Japan. ${ }^{3}$ Department of Rehabilitation Medicine, Kyoto University Hospital, Kyoto, Japan. ${ }^{4}$ Department of Orthopedic Surgery, Kobe Central Municipal Hospital, Kobe, Japan. ${ }^{5}$ Department of Orthopedic Surgery, Tango Central Hospital, Tango, Japan. ${ }^{6}$ Department of Orthopedic Surgery, Mayo Health System, Owatonna, USA. IInstitute for Frontier Medical Science, Kyoto University, Kyoto, Japan.

\section{Authors' contributions}

RK designed the study and drafted the manuscript. KN, RK, RI performed experiment procedure, surgery. RK, Rl, TY, SO, TN and SF performed evaluation of behavioral, biochemical and histopathological study. SD participated in the design of the study. All authors read and approved the final manuscript.

\section{Competing interests}

The authors declare that they have no competing interests.

Received: 1 September 2010 Accepted: 28 November 2010 Published: 28 November 2010

\section{References}

1. Evans PJ, Midha R, Mackinnon SE: The peripheral nerve allograft: a comprehensive review of regeneration and neuroimmunology. Prog Neurobiol 1994, 43:187-233.

2. Mackinnon SE, Hudson AR: Clinical application of peripheral nerve transplantation. Plast Reconstr Surg 1992, 90:695-699.

3. Fung JJ, Alessiani M, Abu-Elmagd K, Todo S, Shapiro R, Tzakis A, Van Thiel D, Armitage J, Jain A, McCauley J, Selby R, Starzl TE: Adverse effects associated with use of FK506. Transplantation Proc 1991, 23:3105-3108.

4. Penn I: The problem of cancer in organ transplant recipients. Transplant Sci 1994, 4:23-32.

5. Grand AG, Myckatyn TM, Mackinnon SE, Hunter DA: Axonal regeneration after cold preservation of nerve allografts and immunosuppression with tacrolimus in mice. J Neurosurg 2002, 96:924-932.

6. Jamkun J, Selman SH, Swiercz R: Why drinking green tea could prevent cancer. Nature 1997, 387:561.

7. Cao Y, Cao R: Angiogenesis inhibited by drinking tea. Nature 1999, 398:381.

8. Hyon SH, Kim DH: Long-term preservation of rat pancreatic islets under physiological conditions. J Biotechnol 2001, 85:241-246.

9. Baum CG, Szabo P, Siskind GW, Becker CG, Firpo A, Clarick CJ, Francus T: Cellular control of IgE induction by a polyphenol-rich compound. J Immunol 1990, 145:779-784. 
10. Ikeguchi R, Kakinoki R, Matsumoto T, Hyon SH, Nakamura T: Peripheral nerve allograft stored in green tea polyphenol solution. Transplantation 2005, 79:688-695.

11. Spencer GM, Goa KL, Gillis JG: Tacrolimus, an update of its pharmacology and clinical efficacy in the management of organ transplantation. Drug 1997, 54:925.

12. Undre NA, Stevenson P, Schafer A: Pharmacokinetics of tacrolimus: clinically relevant aspects. Transplant Proc 1999, 31:21S-24S.

13. Przepiorka D, Nash RA, Wingard JR, Zhu J, Maher RM, Fitzsimmons WE, Fay JW: Relationship of tacrolimus whole blood levels to efficacy and safety outcomes after unrelated donor marrow transplantation. Biol Blood Marrow Transplant 1999, 5:94-97.

14. Ikeguchi R, Kakinoki R, Okamoto T, Matsumoto T, Hyon SH, Nakamura T: Successful storage of peripheral nerve prior to transplantation using green tea polyphenol: an experimental study in rats. Exp Neurol 2003, 184:688-696.

15. Matsumoto T, Kakinoki R, Ikeguchi R, Hyon SH, Nakamura T: Optimal conditions for peripheral nerve storage in green tea polyphenol: an experimental study in animals. J Neurosci Methods 1997, 145:255-266.

16. Kobayashi M, Tamura K, Katayama N, Nakamura K, Nagase K, Tutumi T, Niwa M, Iwasaki K: FK506 assay past and present-characteristics of FK506 ELISA. Transplant Proc 1991, 23:2725-2729.

17. Bannasch DL, Bannasch MJ, Ryun JR, Famula TR, Pedersen NC: Y chromosome haplotype analysis in purebred dogs. Mamm Genome 2005, 16:273-280.

18. Murgia C, Pritchard JK, Kim SY, Fassati A, Weiss RA: Clonal origin and evolution of a transmissible cancer. Cell 2006, 126:477-487.

19. Oike F, Talpe S, Otsuka M, Dehoux JP, Lerut J, Otte JB, Gianello P: A 12-day course of FK506 allows long-term acceptance of semi-identical liver allograft in inbred miniature swine. Transplant 2000, 69:2304-2314.

20. Talpe S, Oike F, Dehoux JP, Sempoux C, Rahier J, Otte JB, Gianello P: Posttransplant lymphoproliferative disorder after liver transplantation in miniature swine. Transplant 2001, 71:1684-1688.

21. Udina E, Gold BG, Navarro X: Comparison of continuous and discontinuous FK506 administration on autograft or allograft repair of sciatic nerve resection. Muscle Nerve 2004, 29:812-822.

22. Haisheng $H$, Songjie $Z$, Xin $L$ : Assessment of nerve regeneration across nerve allografts treated with tacrolimus. Artif Cells Blood Substit Immobil Biotechnol 2008, 36:465-474.

23. MacCourtie AS, Merry HE, Wolf PS, FitzSullivan E, Keech JC, Farivar AS, Mulligan MS: Synergistic protection in lung ischemia-reperfusion injury with calcineurin and thrombin inhibition. Ann Thorac Surg 2010, 89:1766-1771.

24. Varilek GW, Yang F, Lee EY, deVilliers WJ, Zhong J, Oz HS, Westberry KF, McClain CJ: Green tea polyphenol extract attenuates inflammation in interleukin-2-deficient mice, a model of autoimmunity. J Nutr 2001, 131:2034-2039.

25. Menegazzi M, Tedeschi E, Dussin D, De Prati AC, Cavalieri E, Mariotto S, Suzuki $\mathrm{H}$ : Anti-interferon- $\beta$ action of epigallocatechin-3-gallate mediated by specific inhibition of STAT1 activation. FASEB J 2001, 15:1309-1311.

26. Watson JL, Vicario M, Wang A, Moreto M, McKay DM: Immune cell activation and subsequent epithelial dysfunction by Staphylococcus enterotoxin $B$ is attenuated by the green tea polyphenol (-)-epigallocatechin gallate. Cell Imuunol 2005, 237:7-11.

27. Aktas O, Prozorovski T, Smorodchenko A, Savaskan NE, Lauster R, Kloetzel PM, Infante-Duarte C, Brocke S, Zipp F: Green tea epigallocatechin-3-gallate mediates T cellular NF-kappa B inhibition and exerts neuroprotection in autoimmune encephalomyelitis. J Immunol 2004, 173:5794-5800.

28. Gold BG, Katoh K, Storm-Dickerson T: The immunosuppressant FK506 increases the rate of axonal regeneration in rat sciatic nerve. J Neurosci 1995, 15:7509-7516.

29. Doolabh VB, Mackinnon SE: FK506 accelerates functional recovery following nerve grafting in a rat model. Plast Reconstr Surg 1999, 103:1928-1936.

doi:10.1186/1749-7221-5-17

Cite this article as: Nakayama et al:: Storage and allogeneic transplantation of peripheral nerve using a green tea polyphenol solution in a canine model. Journal of Brachial Plexus and Peripheral Nerve Injury 2010 5:17.

\section{Submit your next manuscript to BioMed Central and take full advantage of:}

- Convenient online submission

- Thorough peer review

- No space constraints or color figure charges

- Immediate publication on acceptance

- Inclusion in PubMed, CAS, Scopus and Google Scholar

- Research which is freely available for redistribution 